Article

\title{
Agencies' Reputational Game in an Evolving Environment: Europol and the European Parliament
}

\author{
Agathe Piquet \\ Centre for European Research, Queen Mary University of London, UK; E-Mail: a.piquet@qmul.ac.uk
}

Submitted: 7 February 2021 | Accepted: 13 July 2021 | Published: 30 July 2021

\begin{abstract}
With European Union agencies becoming increasingly significant actors in European governance, further research is needed to understand how they interact with their environment. Applying the 'reputation' literature to Europol, this article examines in greater detail how agencies behave with their 'informal' audiences in comparison with the formal ones. It demonstrates that agencies are deeply invested in the shaping of their reputation, including towards their informal audiences especially if the latter represent 'reputational threats.' Based on a quantitative analysis of activity reports and on a qualitative study of the face-to-face engagements of Europol with the European Parliament over time, this research sheds light on the complementary communicative strategies agencies can use to (re)present themselves depending on the dimension of their reputation at stake.
\end{abstract}

\section{Keywords}

autonomy; EU agencies; European governance; Europol; reputation

\section{Issue}

This article is part of the issue "Resilient Institutions: The Impact of Rule Change on Policy Outputs in European Union Decision-Making Processes" edited by Ariadna Ripoll Servent (University of Salzburg, Austria) and Angela Tacea (Vrije Universiteit Brussel, Belgium).

(C) 2021 by the author; licensee Cogitatio (Lisbon, Portugal). This article is licensed under a Creative Commons Attribution 4.0 International License (CC BY).

\section{Introduction}

The agencification, i.e., the proliferation of European Union (EU) agencies since the 1990s, is depicted by some commentators as the "New Paradigm of European Governance" (Magnette, 2005) and has been welldocumented in academic literature. This strong interest holds especially true on some specific dimensions of agencification, for instance the motives behind the creation of agencies or the interrelated matter of control (Geradin et al., 2005; Pollack, 1997; Schout, 2012).

Scholars have also explored how these de novo bodies interact with their environment, especially with their political masters, called 'principals' in the predominant Principal-Agent model. Academic works drawing on this model assume an agent may over time develop its own interests, and have shed light on the different strategies it can use to achieve them, e.g., exploiting the disagreements between its multiple principals (Dehousse,
2008 ) or voluntarily reducing the information asymmetry (Coremans \& Keremans, 2017).

Nonetheless, the instrumental rationality underlying this model tends to elide the role of representations, ideas, and norms from the analysis of agencies' decisions and actions, the latter assumed to be the result of a cost-benefit calculation (Delreux \& Adriaensen, 2017). Furthermore, the explanatory power of the PrincipalAgent model falls short in respect to how agencies behave with those political institutions that do not fit in the category of principals, i.e., not having initiated the delegation of powers to the agency and unable to control it. Indeed, the Principal-Agent model has been mostly elaborated to bring insights on the vertical relationships an agency is part of, and, as such, has an "exclusive focus on hierarchical, dyadic relations" (Delreux \& Adriaensen, 2017, p. 2).

The novel research agenda based on the concept of 'reputation' in the field of EU agencies offers relevant 
insights to resolve these two issues, and is currently migrating from the study of domestic organisations to be applied at the EU stage, notably to understand EU agencies (Busuioc \& Rimkute, 2020a, 2020b; Rimkute, 2020). On one hand, these recent publications have integrated cognitive dimensions in the logics of action and in the trajectory of an agency. On the other hand, these analyses pay attention to the whole environment of an agency, not only reputational issues in respect to its formal political masters but also to its informal audiences (other institutions, media, citizens, interest groups, etc.).

Yet, the existing literature does not fully account if agencies behave differently towards their informal audiences in comparison with their formal ones. One could indeed assume that agencies would prioritise the shaping of their reputation in relation to their formal audiences over the informal ones, reputational issues being a priori more critical with the former as they have legal powers to control them, and even to sanction them (Bach et al., 2021). A way to explore this question is by comparing whether agencies adapt their reputational strategies when informal audiences turn into formal ones following changes of their legal basis. In that sense, we suppose agencies would anticipate and react to such legal transformations by further trying to shape their reputation in accordance with what they believe are the expectations of their new master, so as to maintain a strong level of autonomy.

To test this expectation, this article focuses on the case of Europol, the EU law enforcement agency in charge of facilitating the cooperation between national law enforcement to fight crime and terrorism through information exchanges, operational analysis, and expertise. Created in 1995 as an intergovernmental organisation, Europol became an EU agency when the 1995 Europol Convention (Council Act of 26 July 1995, 1995) was replaced in 2009 by the Europol decision (Council Decision of 6 April 2009, 2009). This formal transformation, reinforced by the 2016 Europol regulation (Regulation (EU) 2016/794, 2016) replacing the 2009 decision, meant that, after having been an informal audience deprived of any power on Europol for almost 15 years, the EP acquired the status of formal audience. Acting as a principal together with the Council and the European Commission, it can now modify the competences and design of the agency and it has gained access to more information, obtained budgetary authority on the agency, and extended the topics on which it has to be consulted by the Council. This article thus explores whether Europol has intended to adjust its reputation to satisfy the EP, i.e., whether a change is visible in the reputational strategy of the agency to conform MEPs' expectations after legal changes were performed in 2009. Reputational strategy seems even more necessary in this case study as the EP was very critical of Europol in the early 1990s (Resolution B4-0732/95, 1995; Resolution A4-0061/96, 1996), confirming its own reputation of a liberal institution (Ripoll Servent, 2018;
Ripoll Servent \& Trauner, 2014) and posing therefore 'reputational threats' to the agency (Gilad et al., 2015). Based on the existing academic studies of the EP, risks could exist therefore that MEPs would start using their newly acquired formal prerogatives as soon as possible to restrict or at least slow down the autonomy of Europol, a security-driven and long-time intergovernmental agency, in the name of a better balance with freedom and of democracy.

The article proceeds as follows. First, it presents the theoretical framework on which this study is grounded, built around the concept of reputation. Then, based on the existing scholarship, interviews and parliamentary debates and reports, we detail the EP's representations in respect to Europol to fully operationalise our research assumption, before detailing our quantitative and qualitative methodology. Finally, we shed light on the absence of a sudden shift following the 2009 EP's empowerment. This continuity shows that the agency has been careful about the dominant representations of this audience since the start of its activities. In doing so, our contribution to the literature on agencies' behaviour and reputation is twofold. On one hand, the variations in terms of content between activity reports and face-to-face engagement indicate that agencies have a differentiated use of the communication tools from their repertoire. On the other hand, agencies do not strictly prioritise formal audiences over informal ones, they rather seem to address what they perceive as the main sources of reputational threats.

\section{Reputation as a Social Representation}

While the idea of reputation has been used to study bureaucratic and organisational behaviours as soon as the 1950s (Maor, 2018), the first conceptual works on it and definitional attempts are much more recent. They are mostly attributed to Daniel Carpenter $(2001,2010)$ who defined it as "the set of beliefs about an organisation's capacities, intentions, history, and mission that are embedded in a network of multiple audiences" (Carpenter, 2010, p. 45). This scholar offered new perspectives on agencies by accounting for the complexity of their environment due to the "existence of multiple expectations by multiple audiences and the context of today's knowledge society and blame culture" (Maor, 2018, p. 18). Mainly applied to the domestic stage, the concept of reputation is increasingly used to analyse agencies at the EU level, where the above-mentioned characteristics tend to be exacerbated (Rimkute, 2020). These works start from three considerations.

Firstly, reputation is thought as multifaceted. Four dimensions of reputation can be distinguished (Carpenter, 2010). Two relate to the outputs: the technical (does the agency possess sufficient technical and analytical capacity and skills?) and performative (does the agency fulfil its formal missions and attain its goals?) aspects. The other two are rather about the agency's 
inputs: the legal-procedural (does the agency follow fair procedures and rules?) and moral (does the agency engage in ethical behaviour and contribute to the safeguarding of the most important values?) reputational matters. Therefore, studying an agency's reputation cannot be simplified to observing whether an agency does or does not have a reputation per se, rather it means the identification of the technical, performative, legal-procedural and moral reputation of an agency. As expressed by Carpenter and Krause:

If reputation is reduced to simply a binary or monotonic choice or outcome pertaining to what a public agency has or does not have, or that an agency has 'more' or 'less' of, much of the richness of administrative behaviour will be lost to the analyst. $(2012$, p. 31)

Secondly, the reputation literature pays specific attention to audiences. Indeed, reputation is how different audiences perceive what an agency is and does. Audiences are "any individual or collective that observes a regulatory organisation and can judge it" (Carpenter, 2010, p. 33). They can be formal, what the PrincipalAgent model calls 'principals,' or informal, the constellation of actors and organisations being part of the agency's environment. Each of these audiences has its own representations since every audience evaluates the identity and activities of the agency according to its own norms. Furthermore, not all audiences will value the same dimension of an agency's reputation according to their own dominant values and criteria. For instance, some will be more attached to performative or technical facets, pushing the moral and legal-procedural ones to the background. Considering these elements is crucial as, argued by Carpenter and Kraus, "audience members' behaviours toward government agencies are a function of their beliefs" (2012, p. 26).

Thirdly, reputation as a set of beliefs is not immutable or frozen; it can evolve. Agencies themselves can try to act upon their perceptions among external audiences through communicative strategies, whether to cultivate their reputation when it is positive or, above all, to change the representations of themselves held within their environment when those are negative. Communication can also be used to model the expectations of audiences (Busuioc \& Rimkute, 2020b; Wood, 2018). Scholars have highlighted how agencies are usu- ally very active in their communication as their autonomy is a function of their reputation. Autonomy can be defined as the capacity of an agency to implement its own ideas, to deal with its own business and to benefit from a certain leeway in its actions and decisions (Busuioc et al., 2011; Carpenter, 2001; Groenleer, 2009). To this end, scholars have shown that reputation turns out to be an 'asset' (Maor, 2018; Rimkute, 2020). Indeed, when an agency meets the expectations of its formal audiences about its capacities, intentions, history, and mission, audiences are more encouraged to extend its formal mandate and authority and/or have fewer motives to exert control over it and hence to restrict its autonomy (Carpenter, 2010; Gilad \& Yogev, 2012; Maor, 2018). This holds true even in respect to informal audiences insofar as they would offer support to an agency whose representations comply with all their beliefs. That support can be crucial for agencies to avoid criticism and disempowerment or to fulfil their tasks, as they rarely benefit from constraining powers. In gaining that support, agencies can expand their autonomy beyond their formal powers (Busuioc \& Rimkute, 2020a, 2020b).

Nevertheless, agencies can only try to shape their reputation; the results of their actions are not guaranteed and are not always the ones they hoped for. Indeed, reputation being multi-faceted, agencies need to juggle to find the right balance between the four components mentioned above and can struggle in this process (Busuioc \& Rimkute, 2020a; Carpenter, 2010). In addition, in their attempt to gain support from one audience, agencies take the risk of alienating others that have different norms. Consequently, agencies do not fully control how their communication will be interpreted by external actors and can be confronted with the need to make difficult decisions on the dimension of their reputation they choose to emphasise the most and on what support they need the most. In that situation, scholars have identified that agencies would be "selectively responding to, and actively shaping, expectations of audiences 'that matter'-on whose support they depend" (Busuioc \& Rimkute, 2020b, p. 1259).

Yet, little is known about what the key audiences for an agency are, the ones 'that matter,' and whether a distinction between informal and formal audiences is operated by agencies in their reputational communication. A way to explore this research question is to compare the attention paid by an agency to a specific audience, before

Table 1. Summary of organisational reputation dimensions.

\begin{tabular}{ll}
\hline Reputational dimensions & Signals that the agency sends to audiences \\
\hline Technical & Agency sends strong professional and technical signals \\
Performative & Agency emphasises its ability to attain goals set in its formal mandate \\
Legal-procedural & Agency emphasises a thorough engagement in socially acknowledged procedures \\
Moral & $\begin{array}{l}\text { Agency signals its commitment to wide moral implications and the ethical aspects } \\
\text { of its conduct }\end{array}$ \\
\hline
\end{tabular}

Source: based on Rimkute (2020, p. 389). 
and after it acquires formal powers to control and even sanction it. We assume that the agency would adapt to changes of its legal basis by being much more careful about the expectations of this audience and would further try to shape its reputation in accordance with the dominant representations of its new master to preserve the most its autonomy. To test it, this article focuses on the reputational game of Europol, created as an organisation exclusively controlled by national governments before becoming an EU agency with the 2009 decision. This legal change meant that the EP, an informal audience for 15 years, turned into a formal one and gained control and sanction powers, such as hearings of the executive director or blocking of the discharge procedure.

Our initial expectation of the agency strongly adapting its communication after this formal change is even stronger here as the EP could have been perceived by Europol as a source of 'reputational threats,' i.e., of "challenges that pose a threat to the agency's established reputation, consisting of external opinions and allegations from (a) particular audience(s)" (Gilad et al., 2015 p. 452). Indeed, scholars depict the EP as a 'liberal' institution and such position appears in the first very critical public statements the institution issued in respect to Europol, calling for a better data protection framework and more democratic control of the newly created organisation (Resolution B4-0732/95, 1995; Resolution A4-0061/96, 1996). The existing literature has highlighted how, when facing reputational threats, agencies can be very active in their communication to ensure their survival through their annual reports (Rimkute, 2020), public statements (Bach et al., 2021) or even strategically remaining silent (Maor et al., 2013). One could therefore expect that the EP's empowerment in respect to Europol would intensify the perception of these threats, making reputational issues particularly acute for the agency and leading to a sudden adjustment from the agency. To fully verify this assumption, we need first to assess MEPs' expectations towards Europol and then to analyse whether the agency has attempted to further take them into consideration in its communication following the legal empowerment of the EP.

\section{Political Cleavages and Conflicting Expectations within the EP}

The first public judgements issued by the MEPs shed light on the prevalence of the legal-procedural and ethical dimensions in their assessment of Europol. Yet, MEPs' expectations have turned out to be much more complex and the dominant representations within the institution have also evolved following European elections, exogenous events, and formal changes. In this section, we consider political groups as the units of analysis as they reflect ideological stances and are key determinants of the positions adopted by MEPs (Ripoll Servent, 2017). We hence selected quotations that were especially representative of the positions adopted by each political group, whatever the nationality of the individual MEP, at each transformation of Europol's legal bases.

Firstly, the EP is far from being a homogenous institution and its changing composition between the 1990s and the 2010s has impacted the dominant expectations held towards Europol, especially following the electoral successes of the European People's Party (EPP), a right/centre-right wing party. The EPP has exhibited since the 1990s strong concerns for internal security, following the abolition of internal border controls between member states, calling for solutions to solve this problem (Ripoll Servent, 2017). One of the ideas advocated by members of the EPP was the setting up of a structured European police cooperation (EP, 1992) and since then the EPP has had strong expectations in relation to Europol's performance, expecting it to achieve the goals set in its formal mandate: the effective fight against crime and terrorism. This position clearly appears during plenary debates dedicated to Europol's legal bases. For instance, in 2008 various EPP members urged the rest of the hemicycle to support Europol's operational expansion to make it more effective, without waiting for even stronger data protection or a reinforced role for the EP insofar as, according to them: "We need security now, which means we need Europol now" (Hubert Pirker, Austria, EPP; EP, 2008). This position was reiterated during the 2016 plenary debates dedicated to the second reading of Europol regulation, with declarations such as "reinforcing Europol means reinforcing the protection and security of the citizens of the EU" (Stefano Maullu, Italy, EPP; EP, 2016).

While the EPP has gradually become the largest political group within the EP, it was in the early 1990 s only second, behind the Socialist group. Yet, MEPs from this latter group had at that time different expectations towards Europol, as illustrated by their rejection of the 1995 report on Europol convention, written by EPP Harmut Nassauer. Being by then numerically dominant, Socialists were able to oppose the numerous amendments made by the EPP insisting on the risks created by international crime and the urgent need to establish Europol. Their representation was mostly due, in the early 2000s, to the very few powers granted to the EP in Europol's creation and governance. Its intergovernmental nature worsened the existing suspicion in regard to Europol, first announced as a European FBI. This distrust was even stronger as the negotiations of the 1995 Convention were held in a very opaque and secret way, a source of "bred misconceptions" (Busuioc et al., 2011, p. 856) about what Europol was and how it was controlled. The arrest in 2001 of a Europol staff member on the grounds of financial misappropriation did nothing to disperse these fears.

However, socialist MEPs have gradually shifted their expectations towards this agency. They now favour more and more output prospects in relation to the agency and have stopped blocking its operational expansion since the early 2000s. This change appears in 2008 during the 
plenary debates about the new legal basis of Europol: "We are finally in a position to make Europol into a concrete and effective tool in combating organised crime, as well as many other dangerous types of crime which are now manifesting themselves at European level" (Claudio Fava, Italy, PSE; EP, 2008); and then again in 2014 during the debates on Europol regulation: "I believe that a strong cooperation agency for the various police authorities is fundamental in the strategy to fight organised country, and that a strong Europol is important" (Salvatore Caronna, Italy, S\&D; EP, 2014).

The renewed expectations of socialist MEPs are partly due to exogenous events relating to internal security. Indeed, the EP being a majoritarian institution, MEPs are elected by EU citizens who want their concerns to be taken care of by their representatives. Since the 1970s, internal security has become a growing electoral topic (Eurobarometer, 2013, 2018), especially after events as terrorist attacks or major criminal discoveries. EU citizens have hence exerted strong pressures towards their elected representatives to take further steps to guarantee their security. Thus, the previous quotes make clear that, contrary to the early 1990s, socialist MEPs have insisted since the 2000s on the threat international crime and terrorism represent and have been looking for solutions to this problem, contributing to the shift from input reputational aspects being prioritised to the growing importance of output ones.

On top of this potential explanation, a broader normative development of the EP in Justice and Home Affairs has been witnessed by different scholars since the Lisbon Treaty. With its new status of co-legislator in this domain, new norms became dominant as co-decision amplifies the weight of the major political groups and encourages the smaller ones to support the big ones so as to avoid being side-lined (Carrera et al., 2013; Hausemer, 2006; Ripoll Servent, 2010, 2012). In Justice and Home Affairs, it has meant aligning with the EPP's expectations in terms of outputs, as the Council and the EPP, the dominant group since the 1999 elections, have insisted on the need for MEPs to act 'responsibly' (Ripoll Servent, 2010, 2018), i.e., to adopt a 'realistic' stance and to put an end to "Christmas wish lists" (Ripoll Servent, 2012, p. 67).

Nevertheless, MEPs paying more attention and prioritising the output reputational aspects of Europol does not mean that they omitted input dimensions from their expectations nor that reputational threats on the agency have disappeared (Rimkute, 2020). For instance, legal-procedural and moral expectations have not been completely inexistent in the EPP's expectations towards Europol's activities. EPP's concerns regarding the control over the agency and its respect for fundamental rights and freedoms (especially data protection, transparency, and democracy) have been strong since the 1990s. The need for the agency to integrate these two imperatives in its daily work has been recalled by MEPs from this group, in the various reports they wrote on
Europol's legal bases (Resolution A4-0061/96, 1996) or during plenary debates (EP, 2008, 2014).

In addition, similarly to other JHA matters (Ripoll Servent, 2018), one should not over homogenise the EP, as recalled by a former member of Europol's direction:

The views about Europol in the EP are much more diverse and that reflects the diversity of political opinions and interest groups that are in the EP. So, traditionally, you have everything from left to right and up and down, you have many MEPs, who are concerned about privacy issues, secret State agenda and so on, who have traditionally expressed some distrust about institutions like Europol, and some who have been directly challenging Europol's work, being sometimes hostile towards Europol. On the other side, normally on the EPP and towards the right you have people who strongly support the work of Europol, especially in terrorism. (Interview A, former director of Europol, July 2017, The Hague)

Furthermore, some political groups have kept prioritising legal-procedural and moral expectations in respect to Europol, such as MEPs belonging to the European United Left/Nordic Green Left (GUE/NGL) group. This group has not demonstrated a level of concern for internal security similar to the EPP for instance, with very few mentions of it during debates. The main threat to EU citizens and states in these MEPs' eyes does not seem to be international crime or terrorism themselves, but rather any potential breach to citizens' rights and freedoms Europol could be responsible for, in the name of the fight against criminals and terrorists. Contrary to the Socialist group, no major transformation of their expectations is observed in the public declarations of the GUE/NGL group, whether in 2008-"There is no real possibility of controlling the inaccessible citadel of Europol or of restricting its enforcement activities" (Athanasios Pafilis, Greece, GUE/NGL; EP, 2008)-or in 2016-"We are opposed to this agency being granted significant powers while being strongly opaque and out of public scrutiny" (Marina Albiol Guzmán, Spain, GUE/NGL; EP, 2016).

Consequently, European elections, exogenous events and formal changes have made MEPs' representations much more complex in respect to Europol: Not only the agency is expected to effectively fight crime and terrorism and to display specific expertise, but MEPs are also very careful with moral and legal-procedural considerations. What does it mean for the operationalising of our main assumption? The existing literature on reputation has demonstrated that the two 'output' reputational facets are usually dominant in the reputational work undertaken by EU agencies as they reflect their very 'raison d'être' (Busuioc \& Rimkute, 2020b) in the EU regulatory State (Majone, 1997). Indeed, these de novo non-majoritarian bodies would above all be created to deliver solutions to the problems met at the 
EU level through the providing of expertise and knowledge without any political interference. Thus, technical reputation is commonly emphasised by EU agencies as "technocratic expertise [is] the key criterion for legitimation above all others" (Busuioc \& Rimkute, 2020b, p. 1261), and the performative dimension is similarly central in their communicative strategies as "expertise then provides the means through which EU agencies deliver" (Busuioc \& Rimkute, 2020b, p. 1261). Therefore, we could expect that, independently from its legal basis, Europol has also strongly underlined these two reputational dimensions since the start of its activities. Conversely, considering the whole spectrum of the conflicting MEPs' expectations and the reputational threats lead us to assume that Europol's potential adjustments to the EP's empowerment to ensure its own autonomy, and even survival, would be translated by the agency better balancing the different dimensions of its reputation, outputs and inputs. In other words, Europol having anticipated the transformations of its legal basis and attempting to satisfy its new formal audience would be confirmed if in its communications a shift appears from 2009, with Europol equally presenting itself as a performative and ethical organisation holding a high level of expertise and strongly committed to respect the fair and due decision-making processes. We offer to test this assumption through a quantitative and qualitative methodology.

\section{Methodology}

Agencies have different tools at their disposal to shape their reputation. One of these instruments is their annual activity reports. According to Busuioc and Rimkute, "annual reports are an important (and thus far largely untapped) source for mapping how EU agencies present themselves to a broad range of audiences" (2020a, p. 555). Analysing these reports can be useful to understand the reputational game of an agency over time and to trace back its potential changes as it is a requirement for EU agencies to produce activity reports every year. Other tools, not being issued at a similar periodicity, do not offer the same insights in respect to long-term analyses. In addition, far from being a neutral reporting of their activities, these documents are used strategically by agencies which are quite free in their preparation. They purposefully select the information they wish to disseminate and the way it should appear, and hence which facets of their reputation they chose to build and emphasise (Busuioc \& Rimkute, 2020a). The importance of these documents appears in the care agencies take to prepare these reports. Europol illustrates it perfectly. While its first activity reports were quite simple and activities were resumed on a blank page, over the years they have become increasingly sophisticated in respect to their formatting and their content. The efforts invested in the writing of activity reports makes sense when considering the diversity of audiences they are directed to and the role they play in agencies' governance, including in respect to the EP's control. Until 2009 Europol's activity reports were the only information produced by Europol that MEPs had access to. Since then, they are one of the documents MEPs refer to during the budgetary discharge procedure, extracting indicators and numbers from the reports to justify their decision (e.g., EP, 2021). Consequently, these documents appeared until 2009 as the main written channel and, since then, as one of the principal channels for Europol to (re)present itself to MEPs.

These characteristics explain why we paid a specific attention to Europol's annual activity reports from 1999 to 2019. Our expectation in respect to Europol's entrepreneurship vis-à-vis the EP would be confirmed if we observe a potential balance over time, especially in the late 2000s, between the space the agency has granted in these documents to the four dimensions of its activities and identity. Quantitative methods enable us to identify which dimensions of its reputation Europol has showcased from 1999 to 2020 by considering with NVivo their frequency of occurrence in its successive annual activity reports (see Supplementary File 1 for further information).

Three limits to this method can be highlighted. A first comment needs to be made in respect to the 2001 annual report. The latter was not included in the study as it turned out to be unexploitable, the format not allowing any word search. However, as the analysis is based on reports from 1999 to 2019, the absence of one annual report on such a long period of time should not alter our result. Secondly, word counting and quantitative approaches cannot grasp all the nuances as words are used in more complex communication structures and make sense only when reading the whole sentence or even the entire paragraph. This matter is already identified by Busuioc and Rimkute: "If agencies use 'technical' words to convey a 'moral' message our study would not be able to capture it" (2020a, p. 557). Thirdly, even with tests on samples, coding necessarily means that some selecting is performed. Therefore, we cannot pretend to have been exhaustive in this process. Other researchers could have identified different and additional keywords to operationalise the different facets of a reputation, or the list could have been extended. Nevertheless, the way we designed our research strategy pushes those possible biases at the margins and would not question our results, which aim less at offering a precise counting than at rendering the broad evolutions of Europol's communication on a 20-year period. Keeping this research goal in mind also explains why we chose to analyse our results based on trendlines rather than on raw numbers, so as to mitigate the impact of the above-mentioned limitations.

Furthermore, we complemented our quantitative material by a qualitative one as another important communication channel agencies can use in their reputational strategies is "face-to-face engagement" (Wood, 2018, p. 409). The latter is one of the three "entrepreneurship methods" identified by Wood, 
alongside media communication (social media, traditional media, institutional website) and "knowledge development and learning" (training sessions, sharing of expertise). However, these two tools are less relevant in the case of Europol's addressing the EP: While media communication is very broad and Europol has no guarantee MEPs will read it, knowledge development and learning, as "epistemic exercises" (Wood, 2018, p. 410) aiming at strengthening professional skills, are rather directed to other audiences, e.g., law enforcement officials in our case study.

'Face-to-face engagement' covers a range of different activities, such as networking activities, conferences, consultation. It matches with some legal requirements, for instance, the Europol Executive Director, the Chairperson of the Management Board or their Deputies shall appear in front of MEPs when requested (Regulation (EU) 2016/794, 2016, article 51 §2(a)) or Europol activity reports by the Executive Director are requested by the EP (Regulation (EU) 2016/794, 2016, preamble $§ 60)$. Face-to-face engagement also includes non-compulsory practices, such as MEPs visiting the agency's seat. The content of these activities and the way they are used by the agency to shape its reputation are difficult to apprehend through quantitative methods. Instead, we used a qualitative methodology combining different material. An interview with Europol's director, conducted in 2017 and part of a broader research project, is used and complemented by some open-access documents enabling us to understand the face-to-face engagement practices set up by the agency in relation to MEPs (speeches within the European hemicycle, agenda of the visit to the agency's seat in The Hague) and their content. As these instruments involve a limited audience, we could expect the agency to use them for tailormade ends, to particularly answer the expectations of this audience.

\section{A complex Reputational Game}

Our results are detailed as follows. We start by exploring which facets of its reputation Europol has attempted to convey through its annual activity reports, then through face-to-face engagement, in order to confirm whether the agency has anticipated the 2009 transformation of the EP into one of its political masters and to test if it prioritises formal audiences over informal ones. In this case, it would have tried to fulfil its conflicting expectations, balancing the output aspects of its reputation with the input ones.

\subsection{Managing a Multi-Faceted Reputation through Activity Reports}

Applying our quantitative methodology, figure 1 offers a visualisation of the evolution of the appearance percentage of each reputational facet in Europol's activity reports over time.

A first look at this figure seems to confirm what the pre-existing literature on reputation demonstrated: Agencies would become more "reputationally-astute and over time expand their toolbox of reputational strategies" (Busuioc \& Rimkute, 2020a, p. 566). While the technical dimension was clearly predominant over the three other aspects of reputation in 1999, a better balance was gradually achieved. Indeed, the linear trend of the legal-procedural dimension is ascending and so is the moral one, even if to a much lesser extent, with a small bump of both in 2009, when the EP became one of Europol's principals. Here lies a slight difference between our results and the existing literature. For instance, according to Rimkute and Busuioc, while ageing, EU agencies would grant less importance to the moral dimension of their reputation and this decrease would be even stronger for the legal-procedural aspect (2020a).

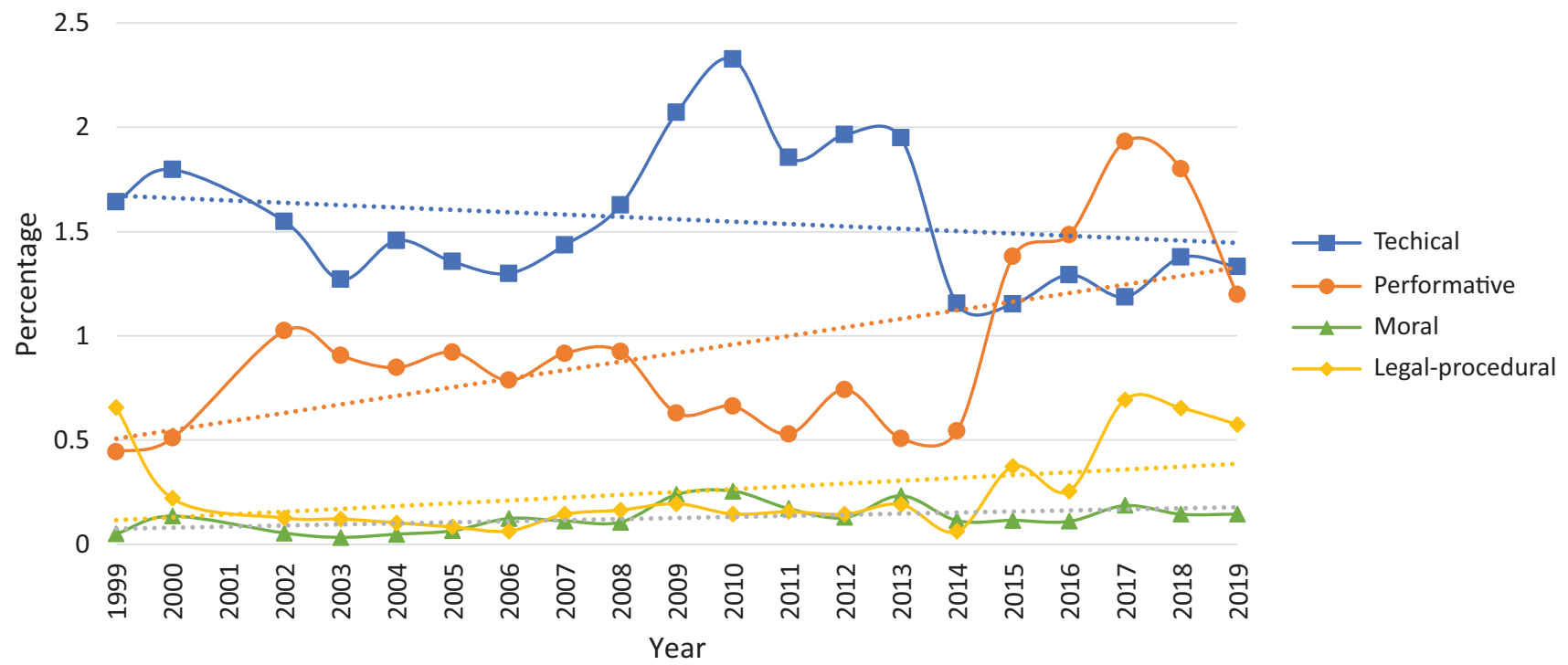

Figure 1. Evolution of the highlighted reputational dimensions. 
In our case study, such result could be a confirmation of Europol anticipating the transformation of its legal basis and the reinforced powers of the EP.

Nonetheless, the biggest 'winner' of the readjustment initiated by Europol over time is its reputational performative facet. It has gained more and more attention in the agency's annual reports, especially since 2015 and the new format of reports (the 'consolidated annual activity report'). In addition, although the linear trend of the technical aspect is descending, no major gap can be witnessed between 1999 and 2019 and this dimension became even stronger in 2009. Therefore, the technical and performative matters have remained the reputational dimensions Europol has emphasised the most since the start of its activities. This imbalance in favour of reputational outputs in Europol's annual reports confirms the existing literature in respect to these dimensions being predominant in the communication issued by EU agencies as they are their 'raison d'être,' even when facing reputational threats (Rimkute, 2020). It also makes sense when taking into account the diversity of audiences targeted by these documents. Annual reports are used by Europol to (re)present itself not only to parliamentarians, but also, among others, to national law enforcement services. The latter had to be convinced of the technical expertise and the capacity of the agency to fulfil its missions, to be effective. Hence, the strong focus of Europol on these two aspects partly relates to the need for the agency to persuade national police officers to enter the data they took time to obtain into the European law enforcement databases.

Although these accounts shed light on the imbalance between its different reputational facets performed by Europol in its activity reports, our research question is far from being answered. While the legal-procedural and moral dimensions have gradually gained more weight in annual reports, this evolution remains limited without any major turning point and the input aspects are still far from the output ones. In other words, Europol does not seem to have suddenly used its annual reports to frame its reputation in accordance with the multidimensional expectations of the EP after the latter became a formal audience. We argue in the following sub-section for the need for researchers to pay attention to the panel of agencies' practices to get the 'full picture' of their interactions with their audiences. This is especially the case of face-to-face engagement, creating more intimate contacts and potentially offering the opportunity to an agency to answer the expectations of a specific audience.

\subsection{Face-to-Face Engagement: A Tailor-Made Tool?}

While performative and technical reputational dimensions have remained predominant over time in comparison with the input aspects in annual activity reports, it appears that Europol has mostly used face-to-face engagements with MEPs to focus more restrictively on the input expectations. Nonetheless, contrary to our expectations, the agency has not simply adjusted its communication after the EP formally became one of its political masters able to control it: Europol has paid attention to the EP's representations since it started its activities in the 1990s, demonstrating its strong care to informal audiences.

Indeed, as soon as the 1990s, effective face-to-face exchanges were initiated by Europol and went beyond the legal requirements. In the 1990s, without being compelled to do it, Europol answered regularly to the MEPs' information requests, sent them information, planned visits of MEPs to its seat in The Hague, and accepted the invitations of the EP's committee on Civil Liberties, Justice and Home Affairs to come to Brussels to explain their activities and answer their questions (Busuioc, 2010; Trauner, 2012). In these circumstances, adding to some public statements (Bruggeman, 2006), representatives of Europol were very active in trying to convince MEPs about the agency's respect for due and fair processes and the ethical nature of its work. For instance, Jürgen Storbeck, the agency's director from 1999 to 2004, stated in front of MEPs that "parliamentary control of Europol is currently unclear," claiming that stronger and more efficient democratic control would be in Europol's own interest (EP, 2003).

In doing so, Europol was willing to reduce information asymmetries so as to mitigate the existing doubts and critics addressed to the agency by MEPs, although they were only an informal audience, according to one of Europol's former directors:

The more I have been involved and the more Europol has been exposed to the EP, the better it has been to demystify Europol. Some of the assumptions that we are collecting despite of privacy rights are eroded because of the way in which Europol is managing this and is taking privacy concerns in a very strong way. (Interview A)

This attempt to positively shape its legal-procedural and moral reputations by presenting itself as willing to be more controlled than the legal requirements, more transparent, and more attentive to data protection issues persisted in the 2000s and 2010s. For instance, in its 2010 annual report, Europol submitted the idea of its multiannual and annual working programmes to be discussed by the EP and called for more frequent visits from MEPs to be scheduled to its seat. These visits are opportunities for Europol to present aspects of governance, oversight, financial and administrative management, data protection, alongside more operational briefings (EP, 2017; Europol, 2013). Similarly, Europol wrote a very detailed information note for the EP about the transfer of financial data from the agency to the United States. Without being obliged to do it, the aim of the agency was to reassure MEPs about its activities (Trauner, 2012). Finally, a former Europol's director explained to us how 
he multiplied his trips to Brussels to appear more transparent and subject to democratic control:

Europol becoming an EU agency and becoming more integrated therefore into the EU institutions domain allowed me as the director to appear much more frequently before the LIBE committee to meet more frequently MEPs. And I think it has led many MEPs to feel a little bit of ownership for Europol. So today Europol has probably the most positive profile or reputation in the EP for a long time. (Interview A)

If a more systematic exploration of face-to-face engagement practices is required, it nonetheless appears in the above-mentioned examples that Europol has initiated itself direct interactions with MEPs, even when not required to do so, to shape their representations. However, contrary to what we expected, Europol did not shift its practices following legal changes as it paid attention to MEPs' representations even when they were restricted to the role and powers of an informal audience. Such effort could relate to the perception by an agency of a 'reputational threat' posed by the EP, very critical of its identity and activities in the early 1990s, although it was only an informal audience by that time. EP's public statements on the insufficient democratic control of Europol and on its lack of respect for fundamental freedoms could have been perceived by the agency as detrimental to its autonomy and legitimacy. Therefore, these results confirm the idea that agencies "react to reputational threats through communicative behaviours" (Bach et al., 2021, p. 2). However, we demonstrate here that they can also use face-to-face engagements to address these risks, and not only public declarations (Bach et al., 2021, p. 2), annual reports (Rimkute, 2020) or remaining silent (Maor et al., 2013). This reaction could indicate that the audiences 'that matter' for agencies are not exclusively the ones benefitting from more power on them, but rather the ones posing the highest reputational threats.

\section{Conclusion}

This article offers more insights on the relationship between an agency and its audiences with the concept of 'reputation.' The emerging co-decision norms following formal changes and the renewed context of internal security have contributed to a rebalancing over time between output- and input-oriented expectations for a majority of left-wing MEPs. Together with the electoral victories of right-wing MEPs already driven by technical and performative dimensions, these evolutions lead to complex expectations of MEPs towards Europol without ending reputational threats over the agency. Complementing the existing literature on reputation, audiences, and threats, we demonstrated that these conflicting representations were addressed by Europol through a combination of tools, articulating the different facets of an agency's reputation. In those instruments dedicated to a general audience, Europol mostly emphasised its output reputational aspects-technical expertise and performative power-, corresponding to their 'raison d'être' in the EU regulatory State (Busuioc \& Rimkute, 2020b). Yet, more tailor-made and face-to-face strategies (Wood, 2018) were also deployed by the agency when it came to its input reputational dimensions-legal-procedural and moral facets. Nevertheless, no sudden shift appears in Europol's reputational game following legal changes: No major rupture can be observed in terms of content and strategies after the EP acquired formal powers on the agency. Legal changes have hence only intensified pre-existing dynamics, proving the strong care taken by an agency to (re)present itself to informal audiences and that formal ones are not the only audiences 'that matter.' Based on a single case study, this article calls for further research on EU agencies' differentiated strategies in respect to audiences and to the reputational dimensions at stake. To this respect, a question to explore is whether agencies use face-to-face engagement to shape their reputation on inputs dimensions, while they would rather be more public when their 'raison d'être' reputational dimensions are attacked.

\section{Acknowledgments}

I thank Angela Tacea, Ariadna Ripoll Servent, Adina Maricut, Claudia Matthes and all the participants to the ECPR Joint Session and the consecutive workshop for their very constructive comments.

\section{Conflict of Interests}

The author declares no conflict of interests.

\section{Supplementary Material}

Supplementary material for this article is available online in the format provided by the author (unedited).

\section{References}

Bach, T., Jugl, M., Köhler, D., \& Wegrich, K. (2021). Regulatory agencies, reputational threats, and communicative responses. Regulation and Governance. Advance online publication. https://doi.org/ $10.1111 /$ rego. 12421

Bruggeman, W. (2006). What are the options for improving democratic control of Europol and for proving it with adequate operational capabilities? Studia Diplomatica, 59(1), 163-181.

Busuioc, M. (2010). The accountability of European agencies: Legal provisions and ongoing practices [Doctoral thesis, Utrecht University]. National Academic Research and Collaborations Information System. https://www.narcis.nl/publication/RecordID/ oai\%3Adspace.library.uu.nl\%3A1874\%2F44369/ 
coll/person/uquery/busuioc/id/15/Language/en

Busuioc, M., Curtin, D., \& Groenleer, M. (2011). Agency growth between autonomy and accountability: the European police office as a 'living institution.' Journal of European Public Policy, 18(6), 848-867.

Busuioc, M., \& Rimkute, D. (2020a). Meeting expectations in the EU regulatory state? Regulatory communications amid conflicting institutional demands. Journal of European Public Policy, 27(4), 547-568

Busuioc, M., \& Rimkute, D. (2020b). The promise of bureaucratic reputation approaches for the EU regulatory state. Journal of European Public Policy, 27(8), 1256-1269.

Carpenter, D. P. (2001). The forging of bureaucratic autonomy: Reputations, networks, and policy innovation in executive agencies, 1862-1928. Princeton University Press.

Carpenter, D. P. (2010). Reputation and power: Organisational image and pharmaceutical regulation at the FDA. Princeton University Press.

Carpenter, D. P., \& Krause, G. A. (2012). Reputation and public administration. Public Administration Review, 72(1), 26-32.

Carrera, S., Hernanz, N., \& Parkin, J. (2013). The 'Lisbonisation' of the European Parliament: Assessing progress, shortcomings and challenges for democratic accountability in the area of freedom, security and justice (Working Paper 58). Centre for European Policy Studies.

Coremans, E., \& Keremans, B. (2017). Agents as information asymmetry managers in EU trade policy-making. In T. Delreux \& J. Adriaensen (Eds.), The principal agent model and the European Union (pp. 227-254). Springer.

Council Act of 26 July 1995 drawing up the Convention based on Article K.3 of the Treaty on European Union, on the establishment of a European Police Office (Europol Convention). (1995). Official Journal of the European Union, C 316.

Council Decision of 6 April 2009 establishing the European Police Office (Europol). (2009). Official Journal of the European Union, L 121.

Dehousse, R. (2008). Delegation of powers in the European Union: The need for a multi-principals model. West European Politics, 31(4), 789-805.

Delreux, T., \& Adriaensen, J. (2017). Introduction. Use and limitations of the principal-agent model in studying the European Union. In T. Delreux \& J. Adriaensen (Eds.), The principal agent model and the European Union (pp. 1-34). Springer.

EP. (1992). Report of the Committee on Civil Liberties and Internal Affairs on Europol (26 November 1992). https://www.cvce.eu/content/publication/2005/ 3/7/dbf97a27-8d89-4096-ae63-8579b7081dcf/ publishable_en.pdf

EP. (2003). Report (A5-0107/2003). https://www. europarl.europa.eu/sides/getDoc.do?reference=A52003-0107\&type $=$ REPORT\&language $=E N \&$ redirect
EP. (2008). Debates and explanations of vote on the report on the proposal for a Council decision establishing the European Police Office (EUROPOL) (COM(2006)0817C6-0055/2007-2006/0310(CNS)). https://www. europarl.europa.eu/doceo/document/CRE-6-200801-16-ITM-009_EN.html

EP. (2014). Debates and explanations of vote on the report on the proposal for a regulation of the European Parliament and of the Council on the European Union Agency for Law Enforcement Cooperation and Training (Europol) and repealing Decisions 2009/371/JHA and 2005/681/JHA, first reading (COM(2013)0173C7-0094/2013-2013/0091(COD)). https://www. europarl.europa.eu/doceo/document/CRE-7-201402-25-ITM-006-12_EN.html?textTabled=A-7-20140096

EP. (2016). Debates and explanations of vote on the report on the proposal for a regulation of the European Parliament and of the Council on the European Union Agency for Law Enforcement Cooperation and Training (Europol) and repealing Decisions 2009/371/JHA and 2005/681/JHA, second reading (COM(2013)0173C7-0094/2013-2013/0091(COD)). https://www. europarl.europa.eu/doceo/document/CRE-8-201605-11-ITM-008-02_EN.html

EP. (2017). Fact-finding mission of the Budgetary Control Committee (CONT) to Europol (The Hague, the Netherlands). https://www.europarl.europa.eu/ cmsdata/137223/2017-09-13\%20CONT\%20Mission \%20to\%20Europol\%20-\%20Final\%20 Programme.pdf

EP. (2021). Report on discharge in respect of the implementation of the budget of the European Union Agency for Law Enforcement Cooperation (Europol) for the financial year 2019 (2020/2172(DEC)).

Eurobarometer. (2013). One year to go until the 2014 European elections-Institutional part. https:// www.europarl.europa.eu/pdf/eurobarometre/ 2013/election/synth_finale_en.pdf

Eurobarometer. (2018). Democracy on the move. European elections-One year to go. https://www. europarl.europa.eu/at-your-service/files/be-heard/ eurobarometer/2018/eurobarometer-2018democracy-on-the-move/report/en-one-yearbefore-2019-eurobarometer-report.pdf

Europol. (2013, November 3). President of the European Parliament visits Europol. Europol. https://www. europol.europa.eu/newsroom/news/president-ofeuropean-parliament-visits-europol

Geradin, D., Muñoz, R., \& Petit, N. (Eds.). (2005). Regulation through agencies in the EU: A new paradigm of European governance. Edward Elgar.

Gilad, S., Maor, M., \& Bloom, P. B.-N. (2015). Organizational reputation, the content of public allegations, and regulatory communication. Journal of Public Administration Research and Theory, 25(2), 451-478.

Gilad, S., \& Yogev, T. (2012). How reputation regulates regulators: Illustrations from the regulation of retail 
finance. In T. Pollock \& M. Barnett (Eds.), The Oxford handbook of corporate regulation (pp. 321-340). Oxford University Press.

Hausemer, P. (2006). Participation and political competition in committee report allocation: Under what conditions do MEPs represent their constituents? European Union Politics, 7(4), 505-530.

Groenleer, M. (2009). The autonomy of European Union agencies: A comparative study of institutional development. Eburon.

Magnette, P. (2005). The politics of regulation in the European Union. In D. Geradin, R. Muñoz, \& N. Petit (Eds.), Regulation through agencies in the EU: A new paradigm of European governance (pp. 3-22). Edward Elgar.

Majone, G. (1997). The new European agencies: Regulation by information. Journal of European Public Policy, 4(2), 262-275.

Maor, M., Gilad, S., \& Bloom, P. B.-N. (2013). Organisational reputation, regulatory talk, and strategic silence. Journal of Public Administration Research and Theory, 23(3), 581-608.

Maor, M. (2018). Theorizing bureaucratic reputation. In A. Wæraas \& M. Maor (Eds.), Organisational reputation in the public sector (pp. 17-36). Routledge.

Pollack, M. A. (1997). Delegation, agency, and agenda setting in the European Community. International Organisation, 51(1), 99-134.

Regulation (EU) 2016/794 of the European Parliament and of the Council of 11 May 2016 on the European Union Agency for Law Enforcement Cooperation (Europol) and replacing and repealing Council Decisions 2009/371/JHA, 2009/934/JHA, 2009/935/JHA, 2009/936/JHA and 2009/968/JHA. Official Journal of the European Union, L 135.

Resolution B4-0732/95 of the European Parliament of 19 June 1995 on Europol Convention. Official Journal of the European Union, C 151.
Resolution A4-0061/96 of the European Parliament of 1 April 1996 on Europol. Official Journal of the European Union, C 96.

Rimkute, D. (2020). Building organisational reputation in the European regulatory state: An analysis of EU agencies' communications. Governance, 33(2), 385-406.

Ripoll Servent, A. (2010). Point of no return? The European Parliament after Lisbon and Stockholm. European Security, 19(2), 191-207.

Ripoll Servent, A. (2012). Playing the co-decision game? Rules' changes and institutional adaptation at the LIBE Committee. Journal of European Integration, 34(1), 55-73.

Ripoll Servent, A. (2017). The European Parliament. Palgrave Macmillan.

Ripoll Servent, A. (2018). The European Parliament in Justice and Home Affairs: Becoming more realistic at the expense of human rights. In A. Ripoll Servant \& F. Trauner (Eds.), The Routledge handbook of justice and home affairs research (pp. 385-395). Routledge.

Ripoll Servent, A., \& Trauner, F. (2014). Do supranational EU institutions make a difference? EU asylum law before and after 'communitarization.' Journal of European Public Policy, 21(8), 1142-1162.

Schout, A. (2012). Changing the EU's institutional landscape? The added value of an agency. In M. Busuioc, M. Groenleer, \& J. Trondal (Eds.), The agency phenomenon in the European Union: Emergence, institutionalisation and everyday decision-making (pp. 63-83). Manchester University Press.

Trauner, F. (2012). The European Parliament and agency control in the area of freedom, security and justice. West European Politics, 35(4), 784-802.

Wood, M. (2018). Mapping EU agencies as political entrepreneurs. European Journal of Political Research, 57(2), 404-426.

\section{About the Author}

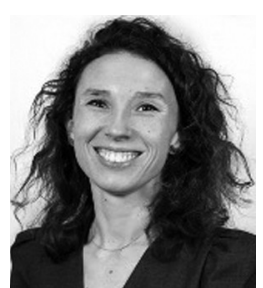

Agathe Piquet is a Postdoctoral Researcher at QMUL and Co-Manager of the NEXTEUK Project on the future of the EU-UK relations, a Jean Monnet Centre of Excellence Project co-funded by the Erasmus + Programme of the European Union. Her research focuses on public policies and internal security, with a strong emphasis on police cooperation, particularly at the EU level. She has published her research in peer-reviewed journals such as the Journal of European Integration or the Journal of Contemporary European Research. 